\section{Psicologia Escolar \\ e Educacional}

ARTIGO

DOI: http://dx.doi.org/10.1590/2175-35392020216145

Elocid - e216145

\title{
ACULTURAÇÃO DE ESTUDANTES PARAGUAIOS NA REGIÃO DE FRONTEIRA BRASILEIRA
}

\author{
Maria Luzia da Silva Santana ${ }^{1} \mathbb{D}$; Cláudia Cristina Fukuda ${ }^{2} \mathbb{D}$
}

\begin{abstract}
RESUMO
O presente estudo teve o objetivo de identificar os padrões de aculturação (assimilação, integração, separação e marginalização) de estudantes paraguaios no contexto escolar brasileiro, considerando a sua adaptação psicológica e sociocultural. Realizou-se um estudo quantitativo com 231 estudantes paraguaios e de descendência paraguaia, com idades entre 13 e 16 anos. A maioria dos estudantes adotou assimilação e integração como estratégias de aculturação e considerou fácil lidar com dois ou três idiomas, usando-os na escrita e na oralidade, o que sugere adaptação psicológica e cultural adequadas.
\end{abstract}

Palavras-chave: Aculturação; estudantes; fronteira brasileira.

\section{Acculturation of paraguayan students in the brazilian frontier region}

\begin{abstract}
This study aimed to identify the acculturation patterns (assimilation, integration, separation and marginalization) of Paraguayan students in the Brazilian school context, considering their psychological and sociocultural adaptation. A quantitative study was carried out with 231 Paraguayan and Paraguayan descendent students aged 13 to 16 years. Most students adopted assimilation and integration as acculturation strategies and found it easy to deal with two or three languages, using them in writing and speaking, which suggests appropriate psychological and cultural adaptation.

Keywords: Acculturation; students; brazilian border.
\end{abstract}

\section{Aculturación de estudiantes paraguayos en la región de frontera brasileña}

\section{RESUMEN}

En el presente estudio se tuvo el objetivo de identificar los patrones de aculturación (asimilación, integración, separación y marginalización) de estudiantes paraguayos en el contexto escolar brasileño, considerando su adaptación psicológica y sociocultural. Se realizó un estudio cuantitativo con 231 estudiantes paraguayos y de descendencia paraguaya, con edades entre 13 y 16 años. La mayor parte de los estudiantes adoptó asimilación e integración como estrategias de aculturación y consideró fácil lidiar con dos o tres idiomas, usándolos en la escritura y en la oralidad, lo que sugiere adaptación psicológica y cultural adecuadas.

Palabras clave: Aculturación; estudiantes; región de frontera.

\footnotetext{
1 Universidade Federal de Mato Grosso do Sul - Campo Grande - MS - Brasil; santanapsi@gmail.com

2 Universidade Católica de Brasília - Brasília - DF - Brasil; claudiafukuda@hotmail.com
} 


\section{INTRODUÇÃO}

Nos contextos escolares fronteiriços, especificamente na fronteira seca entre Ponta Porã, no Mato Grosso do Sul, Brasil, e Pedro Juan Caballero, no Paraguai, observam-se variadas tarefas sociais, incluindo a preocupação com a problemática da identidade cultural (tradições, língua) dos estudantes - principalmente a inquietação com a criação de meios para a valorização e o respeito entre todos, autóctones e migrantes, de maneira que, na sua essência, se contemple a pluralidade e a integração (Pereira, 2009).

Na discussão sobre o interculturalismo, Berry (2013) compreende o termo "aculturação" como o processo de transformação cultural e psicológica vivenciado pelas pessoas em contato intercultural. A aculturação envolve a reciprocidade entre os grupos culturais no decorrer da aculturação, o que implica variados processos e resultados (Sam \& Berry, 2010). Entre as alterações culturais estão os costumes, bem como a vida econômica e política; e as psicológicas envolvem atitudes das pessoas em relação à aculturação e às identidades culturais, aos comportamentos sociais, entre outros (Berry, Phinney, Sam, \& Vedder, 2006). O processo de aculturação, consequentemente, gera adaptação, que inclui o bem-estar psicológico individual e a maneira como as pessoas se gerenciam socioculturalmente (Sam \& Berry, 2010).

As adaptações que os grupos e as pessoas fazem para viver num ambiente em contato com duas ou mais culturas podem ser estressantes ou resultar em alguma forma de acomodação mútua (Berry \& Safadar, 2007), tanto psicológica como sociocultural. A adaptação psicológica, interna, individual, inclui as mudanças psicológicas que a pessoa sofre nos grupos em processo de aculturação e a sua acomodação às novas situações (Berry \& Safadar, 2007). Ela pode levar a mudanças comportamentais bem-sucedidas ou ser problemática, gerando estresse aculturativo (Berry \& Safadar, 2007). Abrange o bem-estar psicológico, a disposição de boa saúde mental e satisfação no novo contexto de convivência cultural. Já a adaptação sociocultural abrange as habilidades sociais para se relacionar, resolver as demandas e os problemas diários (Neto, 2012). Envolve um conjunto de resultados psicológicos que são expressos externamente e possibilitam a interação da pessoa no novo contexto cultural (Berry, 1997a, 1997b).

Segundo Sam e Berry (2010) e Berry (2013), as estratégias de aculturação são integração, assimilação, marginalização e separação. A integração é um processo dinâmico e bidirecional de acolhimento por parte dos imigrantes e dos residentes dos Estados de acolhimento, que acontece em longo prazo e de forma contínua, com acomodação mútua (Berry, 2013). Observa-se um interesse em manter a cultura original e a interação diária com outros grupos, preservando certo grau de integridade cultural, ao mesmo tempo em que se procura, como membro de um grupo étnico e cultural, participar da rede social maior (Berry, 2010).

A assimilação acontece quando os indivíduos não desejam manter sua identidade cultural e sim buscar interação diária com outras culturas (Neto, 2012). Em contraste, a separação acontece quando as pessoas procuram manter sua cultura original e, ao mesmo tempo, evitam a interação com os outros grupos. Já a marginalização é definida quando há pouca possibilidade ou interesse na manutenção cultural, o que resulta, muitas vezes, de exclusão ou discriminação (Berry, 2010).

Na direção da discriminação, o estudo de Pereira (2009) demonstrou a dificuldade de uma estudante originária do Paraguai de distinguir a experiência de atitudes discriminatórias. $O$ preconceito e a discriminação que sofrem os paraguaios no contexto escolar brasileiro - expressos no tratamento diferenciado, nas zombarias e nas chacotas - indicam a defesa de sua identidade brasileira como a única legítima, colocando a outra na posição de inválida ou inferior (Pereira, 2002).

As pesquisas (Dalinghaus, 2013; Melo, Stivanello, da Silva, \& da Silva, 2016; Nunes, 2011), realizadas em escolas públicas de Ponta Porã, evidenciaram a necessidade de (re)conhecimento e valorização das contribuições dos povos para a construção de um fazer educativo voltado às relações interculturais positivas. Mesmo com avanços observados no tocante ao ensino de estudantes bilíngues em Mato Grosso do Sul, é necessário que políticas linguísticas e educacionais possam abarcar a complexidade existente nas escolas localizadas nas regiões de fronteira (Dalinghaus, 2009).

No contexto escolar, espera-se que os estudantes reflitam sobre os conflitos éticos e adquiram conhecimentos, habilidades, valores e atitudes indispensáveis à cidadania, o que envolve o cuidado com os outros e com o meio ambiente (Unesco, 2016). Na visão de Berry (2013), o duplo envolvimento dos imigrantes com sua cultura de origem e a cultura de acolhimento está associado a um maior bem-estar, incluindo melhor satisfação com a vida. Porém, quando há poucas condições para o engajamento no contato intercultural, o nível de bem-estar psicológico e social poderá ser baixo. Além disso, quando os migrantes sofrem discriminação, são suscetíveis a rejeitar um envolvimento estreito com a sociedade de acolhimento e a permanecer mais orientados para o seu próprio grupo étnico. No entanto, quando não são discriminados, consideram seu novo contexto de convivência com o mesmo grau de respeito que lhes foi concedido (Berry et al., 2006).

Partindo desses pressupostos, considera-se que pode existir relação entre as estratégias de aculturação e a adaptação psicológica e cultural de estudantes paraguaios na região de fronteira brasileira. Assim, o 
presente estudo identifica os padrões de aculturação (assimilação, integração, separação e marginalização) de estudantes paraguaios no contexto escolar brasileiro, considerando a sua adaptação psicológica e sociocultural.

\section{MÉTODO}

\section{Participantes}

Participaram 231 estudantes paraguaios e de descendência paraguaia, com idades entre 13 e 16 anos $(\bar{X}=14,08 ; D P=1,31)$ que frequentavam o 7 ㅇ, 8ㅇ e 9o anos do ensino fundamental ii e o 1 o ano do ensino médio, em duas escolas públicas estaduais no município de Ponta Porã, próximas à faixa de fronteira com o Paraguai. Da escola situada no centro da cidade, participaram 110 estudantes, e da escola situada no distrito Sanga Puitã, que faz fronteira com a cidade Zanja Pytã, no Paraguai, participaram 121 estudantes.

Os critérios utilizados para a inclusão foram: falar outra língua além do português, como guarani e/ou espanhol; ter pai e/ou mãe de nacionalidade ou descendência paraguaia; assinar o Termo de Assentimento (TA) e entregá-lo; entregar o Termo de Consentimento Livre e Esclarecido (TCLE) assinado pelo responsável; e responder aos instrumentos da pesquisa.

Utilizou-se a descendência dos estudantes e a língua como critérios de inclusão no estudo porque a maioria dos estudantes possui binacionalidade/dupla nacionalidade. Assim, muitos deles, mesmo sendo de nacionalidade paraguaia e morando nesse país, se consideram brasileiros. Foram excluídos da pesquisa os estudantes que não estavam na faixa entre 12 e 16 anos.

\section{Instrumentos}

Os instrumentos utilizados neste estudo visam obter informações sobre as estratégias de aculturação e adaptação psicológica e sociocultural. As estratégias de aculturação foram mensuradas por meio da Escala de Aculturação para Adolescentes Paraguaios (EAAP); a adaptação psicológica foi verificada mediante a Escala Multidimensional de Satisfação de Vida para Crianças (EMSVC) e a Escala de Afetos; e a adaptação sociocultural foi observada mediante o Questionário de Dados Sociodemográficos.

O Questionário de Dados Sociodemográficos foi desenvolvido para obter informações como idade, sexo, ano escolar, turma, origem identitária do estudante e de seus familiares, adaptação na escola, mediante a observação da ocorrência de repetência ou expulsão e uso de línguas diferentes nesse contexto e em casa.

A EAAP foi adaptada por Santana (2018a) para avaliar a aculturação de adolescentes paraguaios residentes na região de fronteira seca, especificamente entre Ponta Porã, no Brasil, e Pedro Juan Caballero, no Paraguai; e entre Ponta Porã e a cidade de Zanja Pytã, no Paraguai. A escala original, composta por 29 itens, foi desenvolvida por Barry (2001) para avaliar a aculturação de imigrantes da Ásia Oriental nos Estados Unidos.

Essa escala mede quatro dimensões de aculturação: assimilação (8 itens), separação ( 7 itens), integração (5 itens) e marginalização (9 itens) (Anexo A). Numa amostra de 231 estudantes de descendência paraguaia, de 12 a 17 anos, de duas escolas de Ponta Porã, encontrou-se confiabilidade satisfatória para as quatro subescalas de aculturação, sendo os coeficientes de 0,91 para assimilação, 0,78 marginalização, 0,73 para separação e 0,70 para integração (Santana, 2018a).

A Escala de Afetos é constituída de 28 adjetivos descritores de estados afetivos subjetivos, sendo que 14 se referem a afetos positivos e 14 a afetos negativos. As opções de resposta possuíam um formato de escala do tipo Likert de cinco pontos, com a seguinte gradação: "nem um pouco", "um pouco", "mais ou menos", "bastante" e "muitíssimo". A consistência interna medida pelo alfa de Cronbach foi de 0,88 para ambas as subescalas e observou correlações positivas de afeto positivo com autoestima e satisfação de vida, e negativas de afeto negativo com essas variáveis (Segabinazi et al., 2012).

A EMSVA avalia a satisfação de vida de adolescentes nos domínios família, self, self comparado, não violência, autoeficácia, amizade e escola. Essa escala apresentou adequabilidade em todas as subescalas: $\operatorname{self}(\alpha=0,87)$, self comparado $(\alpha=0,85)$, autoeficácia $(\alpha=0,71)$, não violência $(\alpha=0,70)$, família $(\alpha=0,91)$, amizade $(\alpha=0,82)$ e escola $(\alpha=0,87)$ (Segabinazi et al., 2010).

\section{Procedimentos para coleta e análise de dados}

A pesquisa foi aprovada pelo Comitê de Ética em Pesquisa da Universidade Federal de Mato Grosso do Sul (CEP/UFMS), sob o parecer número 2.407.166. O procedimento inicial da pesquisa foi o contato com a direção, os professores e coordenadores que viabilizaram a organização da agenda para o desenvolvimento da pesquisa. Posteriormente, foram realizadas visitas nas salas de aula para apresentação da pesquisa, convite de participação aos estudantes e agendamento das atividades desse estudo.

Os instrumentos foram aplicados em dois momentos: no primeiro, o Questionário de Dados Sociodemográficos e a EAAP e, no segundo, a EMSVA e a Escala de Afetos. A aplicação foi feita nas salas de aula dos estudantes, por meio dos seguintes procedimentos: distribuição dos instrumentos, explicação de que não haveria resposta correta ou errada, prévios esclarecimentos das dúvidas colocadas pelos estudantes, recoIhimento e checagem dos instrumentos preenchidos.

Os dados foram tabulados e transpostos para um banco de dados do software estatístico SPSS (Statistical Package for the Social Sciences) 18.0 for Windows. Realizou-se a inspeção preliminar dos dados com 
a verificação da normalidade, empregando o teste Kolmogorov-Smirnov. Procedeu-se com as análises descritivas dos dados para a caracterização da amostra do estudo conforme escola, sexo, escolaridade, origem e idade. Também se utilizou a estatística descritiva na organização das informações acerca das estratégias de aculturação adotadas pelos estudantes conforme sexo, idade e dificuldade para lidar com mais de uma língua.

Realizou-se, posteriormente, análise das diferenças das estratégias de aculturação adotadas pelo sexo feminino e masculino através do Teste t. Utilizou-se o teste estatístico Coeficiente de Correlação de Pearson para aferir as relações entre estratégias de aculturação e adaptação psicológica (afetos e satisfação de vida) e verificar a direção do relacionamento. Além disso, usou-se a Análise de Variância (Anova) para comparar a distribuição de maneira independente quanto à moradia e às estratégias de aculturação. Para esses testes, 0 parâmetro adotado em nível de significância foi $\leq 0,05$.

\section{RESULTADOS E DISCUSSÃO}

Foi realizada a análise preliminar dos dados, sendo efetuada a reposição dos dados ausentes pela média dos dados do item. Também se observou a normalidade dos dados; o resultado do teste Kolmogorov-Smirnov aceitou a hipótese de normalidade para os dados de aculturação $(s=0,53 ; d f=231 ; p=0,200)$, afetos $(s=0,52$; $d f=231 ; p=0,200)$ e satisfação de vida $(s=0,57 ; d f=231 ;$ $p=0,63)$. Além disso, fez-se a análise da consistência interna dos instrumentos utilizados por meio do teste estatístico Alpha de Cronbach, que apresentaram índices aceitáveis.

Encontraram-se os seguintes índices de consistência interna na EAAP: assimilação $(\alpha=0,910)$, marginalização $(\alpha=0,782)$, separação $(\alpha=0,733)$ e integração $(\alpha=0,704)$; escala de afetos $(\alpha=0,703)$, afetos positivos $(\alpha=0,894)$ e afetos negativos $(\alpha=0,814)$; escala multidimensional de satisfação de vida para adolescentes $(\alpha=0,788)$, self $(\alpha=0,752)$, self comparado $(\alpha=0,772)$, não violência $(\alpha=0,774)$, família $(\alpha=0,771)$, amizade $(\alpha=0,733)$ e escola $(\alpha=0,843)$. Um instrumento de medida é considerado confiável quando apresenta Alfa de Cronbach maior ou igual a 0,70 (Nunnally, 1978).

\section{Estratégias de aculturação e adaptação psicológica de paraguaios}

O processo de aculturação é considerado um elemento influenciador do desenvolvimento, pois a cultura constrói o marco normativo e impõe restrições às possíveis formas de mudança durante o desenvolvimento. 0 contato com novas culturas exige novos aprendizados ou interrompe o aprendizado da cultura anterior, podendo ocorrer dificuldades no processo de aculturação devido às interações mantidas pelo sujeito com membros da sua cultura de origem (Berry, 1997b).
Os dados das estratégias de aculturação foram analisados por meio da média dos resultados brutos de cada subfator, aferidos por meio da soma dos pontos de cada item, sendo que, para o cálculo da pontuação dos itens negativos, o valor atribuído foi invertido. Organizaram-se as estratégias de aculturação adotadas pelos estudantes paraguaios e de ascendência paraguaia considerando o maior escore obtido pelo respondente entre as subescalas Assimilação, Integração, Separação e Marginalização.

Os dados dos estudantes da região da fronteira brasileira com a paraguaia possibilitam sugerir uma adaptação psicológica, tendo em vista que, do total de 231 participantes da pesquisa, a maioria (197) relatou se sentir integrada ou assimilada. Por outro lado, foi registrada a adoção das estratégias de aculturação, separação e marginalização por 34 estudantes, sendo que 12 deles tinham 14 anos e 6 tinham 15 anos (Tabela 1).

Observou-se a média das respostas dos participantes nessas estratégias de aculturação: Assimilação ( $\bar{X}=3,38$; $D P=1,03)$, Integração $(\bar{X}=3,29 ; D P=, 977)$, Separação $(\bar{X}=2,06 ; D P=, 744)$ e Marginalização $(\bar{X}=2,45 ; D P=, 776)$. Organizaram-se as estratégias de aculturação conforme o sexo, obtendo-se para assimilação $(n=51)$ do sexo masculino e $(n=60)$ do sexo feminino; para integração, $(n=41)$ do sexo masculino e $(n=45)$ do sexo feminino; para separação, $(n=8)$ em cada um dos sexos; e para marginalização, $(n=7)$ do sexo masculino e $(n=11)$ do sexo feminino.

Também foi realizada análise de comparação de médias, por meio do Teste $t$, entre os sexos e as estratégias de aculturação. Encontraram-se diferenças entre os sexos para a estratégia de aculturação marginalização, sendo que as meninas $(\overline{\mathrm{X}}=2,5 ; D P=, 762)$ apresentaram médias maiores que as dos meninos ( $\bar{X}=2,3 ; D P=, 769)$, ( $t(231)=2,92 ; p<0,05)$.

$O$ gênero é uma variável que influencia o processo de aculturação. Há evidências substanciais de que as mulheres têm tendência mais elevada para apresentar problemas que os homens (Berry, 1997a). A maioria dos resultados de pesquisa sugere que as mulheres são mais propensas a experienciar uma relativa carência de envolvimento com a cultura de acolhimento e menos habilidades da cultura receptora (Beiser et al., 1988 conforme citado por Neto, 2012). Isso pode ter relação com o status da mulher na sua cultura de origem e na de acolhimento (Berry, 1997a).

No contexto paraguaio, sabe-se que, em 1985, o Código Civil promulgado, em seu primeiro livro, trazia uma série de normas retrógradas em relação à família e às mulheres paraguaias. Houve um retrocesso em relação à Constituição Paraguaia de 1967 , que amparava e legalizava a igualdade sem discriminação entre muIheres e homens (Szwaco, 2012). Assim, é possível que as questões culturais, sociais e históricas do Paraguai, 
Tabela 1. Estratégias de Aculturação por Idade.

\begin{tabular}{lcccc}
\hline Idade & $\begin{array}{c}\text { Assimilação } \\
\mathbf{n}(\%)\end{array}$ & $\begin{array}{c}\text { Integração } \\
\mathbf{n}(\%)\end{array}$ & $\begin{array}{c}\text { Separação } \\
\mathbf{n}(\%)\end{array}$ & $\begin{array}{c}\text { Marginalização } \\
\mathbf{n}(\%)\end{array}$ \\
\hline 12 & $14(6,1)$ & $10(4,3)$ & $1(0,4)$ & $2(0,9)$ \\
13 & $30(13)$ & $19(8,2)$ & $3(1,3)$ & $6(2,6)$ \\
14 & $26(11,3)$ & $20(8,7)$ & $7(3)$ & $5(2,2)$ \\
15 & $24(10,4)$ & $23(10)$ & $3(1,3)$ & $3(1,3)$ \\
16 & $12(5,2)$ & $12(5,2)$ & $2(0,7)$ & $1(0,4)$ \\
17 & $5(2,2)$ & $2(0,9)$ & - & $1(1,4)$ \\
Total & $111(48,1)$ & $86(37,2)$ & $16(6,9)$ & $18(7,8)$ \\
\hline
\end{tabular}

Fonte: Dados da pesquisa.

ou seja, o status de mulher nesse país, tenham influenciado o fato de as meninas relatarem médias maiores na estratégia de aculturação marginalização do que as apresentadas pelos meninos.

A respeito dos dados sobre local de moradia e nacionalidade, tendo como base o resultado da análise de variância (Anova), observou-se que quem mora em Ponta Porã percebe maior assimilação do que quem mora em Pedro Juan Caballero $[F(4,506)=6,133, p<0,001]$. $E$ quem se considera brasileiro tem maior integração $[F(4,763)=4,457 p<0,001]$, sendo menos marginalizado do que quem é brasiguaio $[F(3,145)=7,092, p<0,001]$. No estudo de Berry et al. (2006), 973 jovens relataram alta proficiência e uso da língua étnica, mas também relataram baixa identidade étnica. Eles tinham pouca proficiência na língua nacional e descreveram uma identidade nacional um tanto baixa e pouco contato com indivíduos nacionais. Também endossaram três atitudes de aculturação contraditórias: assimilação, marginalização e separação. Esse padrão inconsistente sugere que esses jovens estão incertos quanto ao seu lugar na sociedade, talvez desejando fazer parte da sociedade maior, mas sem as habilidades e a capacidade de estabelecer contatos (Berry et al., 2006).

Foi realizada a análise de correlação de Pearson com os dados de aculturação dos estudantes com os escores de afetos e satisfação de vida. Encontrou-se uma correlação inversa entre as estratégias de aculturação, separação e marginalização com afetos positivos, satisfação de vida, self comparado, não violência, família, amizade e escola (Tabela 2).

Também pode ser verificada uma correlação positiva entre as estratégias de aculturação, integração e assimilação com os escores de afetos, afetos positivos, multidimensional de satisfação de vida, não violência, amizade e escola. É possível sugerir que

Tabela 2. Correlações entre as Estratégias de Aculturação e Adaptação Psicológica.

\begin{tabular}{|c|c|c|c|c|}
\hline Fatores associados & Assimilação & Integração & Separação & Marginalização \\
\hline Escala de afetos &, $258 * *$ &, $326 * *$ &,$- 217^{* *}$ & - \\
\hline Afetos positivos &, $346 * *$ &, $440 * *$ &,$- 456 * *$ &,$- 442 * *$ \\
\hline Afetos negativos & - &,$- 144^{*}$ & ,301** &, $451 * *$ \\
\hline $\begin{array}{l}\text { Escala Multidimensional de Satisfação } \\
\text { de Vida para Adolescentes }\end{array}$ &, $312 * *$ &, $384 * *$ &,$- 471 * *$ &,$- 462 * *$ \\
\hline Self & - &, $187^{* *}$ & - &,$- 333 * *$ \\
\hline Self comparado & ,129* & - &,$- 353 * *$ &,$- 356 * *$ \\
\hline Não violência &, $393 * *$ &, $373 * *$ &,$- 375^{* *}$ &,$- 335 * *$ \\
\hline Família & - & - &,$- 259 * *$ &,$- 256 * *$ \\
\hline Amizade &, $254 * *$ & ,355** &,$- 372 * *$ &,$- 431 * *$ \\
\hline Escola &, $364 * *$ & ,360** &,$- 414 * *$ &,$- 251 * *$ \\
\hline
\end{tabular}

${ }^{*} p<0,05 .{ }^{* *} p<0,01$.

Fonte: Dados da pesquisa. 
os estudantes integrados ou assimilados descrevem características positivas, incluindo autoestima, bom humor, capacidade de se relacionar e demonstrar afeto, realização de avaliações comparativas positivas com seus pares nos conteúdos relacionados ao lazer, à amizade e à satisfação de desejos e afetos. Têm também baixo índice de comportamentos agressivos, utilizam mais descritores de um ambiente familiar saudável, harmônico, afetivo, de relacionamentos satisfatórios, consideram os relacionamentos com pares de maneira positiva, têm o contexto escolar como importante, mantendo relacionamentos interpessoais favoráveis, e têm nível de satisfação adequado em relação a esse ambiente.

Contudo, as correlações encontradas foram baixas ou moderadas. Assim, observaram-se correlações positivas moderadas entre afetos positivos e integração $(r=, 440 ; p<0,01)$ e afetos negativos e marginalização $(r=, 451 ; p<0,01)$. Também puderam ser percebidas correlações negativas moderadas entre afetos positivos e separação $(r=-, 456 ; p<0,01)$ e marginalização $(r=$ -,442; $p<0,01)$; satisfação de vida e separação ( $r=-, 471$; $p<0,01)$ e marginalização $(r=-, 462 ; p<0,01)$; amizade $e$ marginalização $(r=-, 431 ; p<0,01)$; e escola e separação $(r=-, 414 ; p<0,01)$. Neto (2012) pesquisou acerca da satisfação com a vida em adolescentes de famílias imigrantes portuguesas na Suíça e encontrou correlações entre a satisfação com a vida e identidade portuguesa; 0 domínio e a autoestima foram significativos e positivos, sendo significativas e negativas as correlações entre a satisfação e a percepção de discriminação e os sintomas psicológicos.

\section{Estratégias de aculturação e adaptação sociocultural}

A adaptação sociocultural refere-se à aprendizagem de competências sociais que possibilitam interagir no novo contexto cultural, lidar com os problemas cotidianos e resolver eficazmente as atividades diárias (Neto, 2012). Nesse sentido, as atividades escolares constituem elementos de adaptações socioculturais, incluídas as avaliativas que requerem dos estudantes bom desempenho na sua resolução e domínio do português, tendo em vista que essa língua é a oficial brasileira, adotada nas escolas desse país.

Nos dados dos participantes da pesquisa, observou-se que, na estratégia de aculturação assimilação, 36 respondentes relataram ter dificuldade em alguma disciplina, enquanto 75 apontaram que não; 26 estudantes integrados apontaram dificuldade em alguma disciplina, já 60 responderam que não. Nas estratégias de separação e marginalização, obteve-se um maior número de respondentes com dificuldades, sendo 13 para cada estratégia, enquanto na estratégia separação 5 respondentes apontaram não ter encontrado dificuldade; na marginalização, 3 indicaram não ter dificuldades. De acordo com Neto (2012), o conhecimento do idioma, numa nova sociedade e cultura, facilita a adaptação do imigrante e fornece preparação para emitir respostas aos novos problemas. Assim, é possível que a dificuldade apresentada nas disciplinas escolares se relacione com gestão da língua portuguesa nesse contexto escolar de fronteira brasileira. Observam-se atitudes desfavoráveis à presença das línguas espanhol e guarani no contexto de escolas brasileiras. A presença de estudantes bilíngues “... representa um problema para alguns professores das escolas brasileiras, as práticas linguísticas próprias da fronteira são, portanto, igualmente críticas" (Berger, 2015, p.181).

Também foram observadas nesta pesquisa as estratégias de aculturação e a facilidade dos estudantes para lidar com duas ou três línguas ao mesmo tempo. A maioria dos estudantes assimilados e integrados relatou ter facilidade para lidar com os idiomas. Assim, na assimilação, 83 responderam ter facilidade, 25 acreditam não ser fácil e 3 consideraram mais ou menos fácil; na integração, 76 acreditaram ser fácil, 7 apontaram que não era fácil e 3 acreditaram ser mais ou menos fácil; na separação, 4 estudantes falaram ser fácil e 12 consideraram não ser fácil; na marginalização, 5 descreveram ser fácil e 13 acreditaram ser difícil.

Na fronteira entre Pedro Juan Caballero e Ponta Porã, há uma demanda maior por aprender o português do que o espanhol, aspecto que pode ser explicado pelo interesse comercial e pelo preconceito linguístico existente em relação ao guarani (Dalinghaus, 2013). Quem não fala português tem mais dificuldade de interação com os colegas na escola. Em contrapartida, a apropriação da língua oficial brasileira facilita as relações nesse espaço (Melo et al., 2016).

A apropriação da língua portuguesa pelos paraguaios que moram na região de fronteira entre Ponta Porã e o Paraguai é importante, pois é tida como elemento de ascensão social e influencia os familiares dos estudantes paraguaios no Brasil (Melo et al., 2016; Ramos, 2014). Esse aspecto é corroborado com os dados da presente investigação, pois é considerável o índice de estudantes que utilizam o português na comunicação em casa e na própria escola. Dos 231 estudantes, 141 se comunicam em casa somente em português; 5 em guarani e 7 em espanhol. Os demais estudantes utilizam o português e outras línguas. Assim, é possível hipotetizar que o português é a língua mais presente no contexto familiar dos participantes dessa pesquisa, sendo também a mais utilizada nas escolas de fronteiras brasileiras que atendem estudantes paraguaios ( $n=174)$ (Tabela 3).

Os estudantes oriundos do Paraguai estão sujeitos a um fenômeno denominado diglossia, que é o uso de dois ou mais códigos linguísticos na mesma comunidade. A pesquisa observou que o guarani é a língua menos 
Tabela 3. Estratégias de Aculturação e Língua Usada em Casa e na Escola.

\begin{tabular}{lcccc}
\hline Língua usada em casa & Assimilação & Integração & Marginalização & Separação \\
& $\mathbf{n}(\%)$ & $\mathbf{n}(\%)$ & $\mathbf{n}(\%)$ & $\mathbf{n}(\%)$ \\
\hline Guarani & $3(1,3)$ & $1(0,4)$ & - & $1(0,4)$ \\
Espanhol & $2(0,9)$ & $3(1,3)$ & $2(0,9)$ & - \\
Português & $77(33,3)$ & $47(20,3)$ & $10(4,3)$ & $7(3,0)$ \\
Guarani e espanhol & - & $1(0,4)$ & - & $3(1,3)$ \\
Guarani e português & $4(1,7)$ & $9(3,9)$ & $2(0,9)$ & - \\
Espanhol e português & $17(7,4)$ & $12(5,2)$ & $1(0,4)$ & $1(0,4)$ \\
Guarani, espanhol e português & $7(3)$ & $12(5,2)$ & $3(1,3)$ & $4(1,7)$ \\
\hline Espanhol, português e outros & $1(0,4)$ & $1(0,4)$ & - & - \\
\hline Língua usada na escola & & & & \\
Espanhol & $1(0,4)$ & - & $1(0,4)$ & - \\
Português & $92(39,8)$ & $61(26,4)$ & $11(4,8)$ & $10(4,3)$ \\
Guarani e português & $1(0,4)$ & $4(1,7)$ & $2(0,9)$ & $1(0,4)$ \\
Espanhol e português & $14(6,1)$ & $13(5,6)$ & $3(1,3)$ & $1(0,4)$ \\
Guarani, espanhol e português & $2(0,9)$ & $8(3,5)$ & $1(0,4)$ & $4(1,7)$ \\
Outros & $1(0,4)$ & - & - & - \\
\hline
\end{tabular}

Fonte: Dados da pesquisa.

utilizada na comunicação na escola $(n=8)$ e aparece associado ao uso do português. Segundo Dalinghaus (2013), no Paraguai, o guarani é considerado inferior ao espanhol; assim, os estereótipos em torno dessa língua acontecem de maneira duplicada no contexto escolar brasileiro e no território paraguaio. Essa ideia pode ser deduzida ao considerar que a maioria dos participantes da pesquisa sabe ler $(n=169)$ e escrever $(n=139)$ nas duas línguas predominantes e mais valorizadas nessa região de fronteira, o português e o espanhol. Desses índices, houve um número maior de estudantes culturalmente integrados e assimilados (Tabela 4).

Embora não tenha havido relato do uso do guarani no contexto escolar, os estudantes ressaltaram saber escrever $(n=2)$ e ler $(n=55)$ nesse idioma. Segundo Pereira (2009), no contexto escolar brasileiro, os estudantes paraguaios experienciam diversas referências identitárias; na maioria das vezes, usam o português e, em algumas situações - como para xingamentos e assuntos particulares -, o guarani como meio para confundir os professores e outras autoridades. Nas relações familiares, falam suas línguas de origem - espanhol e guarani - (Pereira, 2009), o que não foi demonstrado nos dados desta pesquisa, haja vista que a maioria utiliza também o português no contexto familiar.

Durante a aculturação, a língua é tida como um dos elementos centrais do contato intercultural, assim como as interações com os pares de seu próprio grupo e de outros grupos etnoculturais (Neto, 2012). Cabe à instituição escolar se engajar no desenvolvimento e na implantação de práticas que possibilitem a integração dos estudantes que não têm o português como língua materna. Uma educação centrada em atender ao grupo de origem majoritária deixa à margem a relevância dos demais grupos que convivem no mesmo contexto, podendo estimular relações interpessoais fragilizadas.

A análise dos achados desse estudo aponta que a maioria dos estudantes paraguaios e de ascendência paraguaia está integrada ou assimilada em escolas brasileiras. Contudo, houve estudantes que adotaram a marginalização ou a separação como estratégias de aculturação, que são consideradas preditores significativos de problemas na saúde mental (Neto, 2012). Isso requer uma prática educativa voltada para a cidadania global, abrangendo as três dimensões conceituais da aprendizagem cognitiva, comportamental e socioemocional. Nesse contexto de escolas de fronteira, consideram-se necessários investimentos para que todos os estudantes experimentem um sentimento de pertencer à humanidade comum, compartilhem valores e responsabilidades, com base nos direitos humanos, e desenvolvam atitudes de empatia, solidariedade e respeito às diferenças e à diversidade (Unesco, 2016).

$O$ resultado desta pesquisa possibilita sugerir aos educadores, principalmente aos professores e demais envolvidos no contexto escolar, que compreendam e fa- 
Tabela 4. Estratégias de Aculturação e Idioma que Sabe Ler e Escrever.

\begin{tabular}{lcccc}
\hline Idiomas que sabe escrever & Assimilação & Integração & Marginalização & Separação \\
& $\mathbf{n}(\%)$ & $\mathbf{n}(\%)$ & $\mathbf{n}(\%)$ & $\mathbf{n}(\%)$ \\
\hline Guarani & $1(0,4)$ & - & - & - \\
Espanhol & $1(0,4)$ & - & $1(0,4)$ & - \\
Português & $36(15,6)$ & $14(6,1)$ & $6(2,6)$ & $3(1,3)$ \\
Português e espanhol & $52(22,5)$ & $58(25,1)$ & $7(3)$ & $7(3)$ \\
Guarani e português & - & $1(0,4)$ & - & - \\
Português e outros & $7(3)$ & - & - & - \\
Espanhol, português e outros & $4(1,7)$ & $3(1,3)$ & - & - \\
Guarani, espanhol, português e outros & - & $1(0,4)$ & - & - \\
Outros & $1(0,4)$ & - & - & - \\
\hline Idiomas que sabe ler & & & & - \\
Guarani & $1(0,4)$ & $1(0,4)$ & - & - \\
Espanhol & $2(0,9)$ & - & $2(0,9)$ & $3(1,3)$ \\
Português & $32(13,9)$ & $9(3,9)$ & $7(3)$ & $3(1,3)$ \\
Português e espanhol & $51(22,1)$ & $51(22,1)$ & $5(2,2)$ & $1(0,4)$ \\
Guarani e português & $1(0,4)$ & $1(0,4)$ & $1(0,4)$ & - \\
Português e outros & $5(2,2)$ & - & - & $9(3,9)$ \\
Guarani, espanhol e português & $12(5,2)$ & $19(8,2)$ & $3(1,3)$ & - \\
Guarani, espanhol, português e outros & $3(1,3)$ & $3(1,3)$ & - & - \\
Espanhol, português e outros & $3(1,3)$ & $2(0,9)$ & - & - \\
Outros & $1(0,4)$ & - & - & - \\
\hline
\end{tabular}

Fonte: Dados da pesquisa.

çam na e da sua prática uma educação contextualizada, perpassada por elementos culturais, simultaneamente disseminadora e produtora de culturas. Por meio dos processos educativos ocorridos nos centros de educação infantil, nas escolas e nas universidades, são percebidos em cada postura, em cada gesto, no idioma, no corpo, em cada autor desse espaço, elementos que evidenciam a sua identidade, suas características históricas e sua dinâmica. No contexto educativo, ocorrem intersecções de culturas que, embora dinâmicas, são marcadas por embates e dilemas que contribuem para o desenvolvimento das relações e da subjetividade dos indivíduos. Isso torna esse contexto, ao mesmo tempo, singular e plural.

A psicologia tem muito a contribuir com a inclusão em sociedades interculturais. Especificamente na educação, pode colaborar mediante a psicologia educacional e escolar. Como um dos fundamentos da educação em contextos interculturais, a psicologia educacional pode cooperar para a formação inicial e continuada do docente, oportunizando reflexões teóricas e práticas voltadas para a formação de professores reflexivos, para que a docência seja apropriada como constante objeto reflexão.

A experiência relatada por Santana (2018b) acerca da disciplina Psicologia do curso de formação inicial para professores da área de matemática numa região de fronteira aponta nessa direção. Tal experiência instigou a construção de sequências didáticas voltadas para o reconhecimento e o empoderamento da diferença, bem como o olhar crítico e respeitoso para com a diversidade. Além disso, possibilitou refletir acerca do papel do docente como mediador da interação e relação de estudantes brasileiros e paraguaios.

Ademais, a psicologia escolar tem um papel social relevante e pode colaborar com a integração de estudantes imigrantes em contextos interculturais, haja vista que os psicólogos escolares elaboram políticas educacionais, atuam na escola, "... no planejamento e avaliação de programas de ensino, na capacitação de docentes, nas relações da escola com a família e comunidade, no enfrentamento dos problemas de aprendizagem e de ensino..." (Maluf, 2003, p. 138). Assim, em escolas interculturais o psicólogo pode, com uma postura críti- 
ca e criativa, desenvolver alternativas que contribuam com o coletivo desses contextos no enfrentamento das demandas reais, a exemplo da gestão das línguas guarani e espanhol, que estão presentes em escolas de Ponta Porã, próximas à faixa de fronteira com Pedro Juan Caballero.

\section{CONSIDERAÇÕES FINAIS}

Pesquisas demonstram que há situações em que as relações entre brasileiros e paraguaios são conflituosas na região de fronteira seca, especificamente de Ponta Porã, no Brasil, com Pedro Juan Caballero, no Paraguai. Contudo, nesta pesquisa a maioria ( $n=197$ ) dos estudantes descreveu a adoção de estratégias de aculturação, assimilação e integração. Além disso, eles consideraram fácil lidar com duas ou três línguas, na escrita e na oralidade, o que sugere adaptação psicológica e cultural adequadas.

A adoção desses padrões de aculturação por estudantes paraguaios poderá levar a melhores resultados na sua adaptação psicológica e cultural, incluindo a satisfação com a vida, o afeto positivo, a amizade e as relações no contexto escolar. As relações interculturais entre os estudantes que reconhecem e respeitam as diferenças permitem experiências empoderadoras para o desenvolvimento positivo nos aspectos físico, cognitivo e psicossocial.

Contudo, houve $(n=34)$ estudantes que adotaram as estratégias de aculturação separação ou marginalização. Além disto, encontrou-se correlação moderada positiva entre afetos negativos e marginalização e correlação moderada na direção negativa entre afetos positivos, e separação e marginalização; satisfação de vida e separação e marginalização; e amizade e marginalização. Isso sugere a necessidade de ações educativas interculturais que vão ao encontro da inclusão desses estudantes.

Esta pesquisa colabora à investigação acerca da educação intercultural ao identificar os padrões de aculturação (assimilação, integração, separação e marginalização), considerando a adaptação psicológica e sociocultural. Contudo, outros estudos são necessários para ampliar as investigações acerca do interculturalismo em escolas de fronteira, abarcando variáveis que podem influenciar a adaptação psiológica e sociocultural de estudantes paraguaios nesses contextos.

Nessa perspectiva, aponta-se que são relevantes pesquisas futuras sobre a dimensão normativa e hierarquizada da língua portuguesa em escolas multiculturais. Assim como, investigações acerca do acolhimento de estudantes paraguaios em escolas brasileiras, tendo em vista que poderão aprofundar a crítica sobre as práticas pedagógicas próximas ao imperialismo e colonialismo que talvez influenciam a sua adaptação psicológica e sociocultural.

\section{REFERÊNCIAS}

Barry, D. T. (2001). Development of a new scale for measuring acculturation: the East Asian Acculturation Measure (EAAM). Journal of Immigrant Health, 3(4), 193-197 Recuperado de http://www.psychwiki.com/dms/other/ labgroup/Measufsdfsdbger345resWeek1/Mario/Barry\%20 2001.pdf

Berger, I. R. (2015). Atitudes de professores brasileiros diante da presença do espanhol e do guarani em escolas na fronteira Brasil-Paraguai: elemento à gestão de línguas. Signo y Seña, (28), 169-185. Recuperado de http://revistas. filo.uba.ar/index.php/sys/article/view/264/232

Berry, J. W. (1997a). Immigration, acculturation, and adaptation. Applied Psychology: an International Review, 46(1), 5-68.

Berry, J. W. (1997b). Acculturation: adaptation or development? Commentaries, 52-55. Recuperado de http://www.iaccp. org/sites/default/files/schongflug_1997.pdf

Berry, J. W. (2010). Intercultural relations and acculturation in the Pacific region. Journal of Pacific Rim Psychology, 4(2), 95-102. https://doi.org/10.1375/prp.4.2.95.

Berry, J. W. (2013). Intercultural relations in plural societies: research derived from multiculturalism policy. Acta de Investigación Psicológica, 3(2), 1122-1135. Recuperado de http://www.sciencedirect.com/science/article/pii/ S2007471913709566

Berry, J. W.; Phinney, J. S.; Sam D. L.; Vedder, P. (2006). Immigrant youth: acculturation, identity, and adaptation. Applied Psychology: An International Review, 55(3), 303-332. Recuperado de http://onlinelibrary.wiley.com/ doi/10.1111/j.1464-0597.2006.00256.x/abstract

Dalinghaus, I. V. (2009). Alunos brasiguaios em escola de fronteira Brasil/Paraguai: um estudo linguístico sobre aprendizagem do português em Ponta Porã, MS. Dissertação de mestrado, Unioeste, Cascavel, PR. Recuperado de http:// www.dominiopublico.gov.br/pesquisa/DetalheObraForm. do?select_action $=\&$ co_obra $=140320$

Dalinghaus, I. V. (2013). Cultura, hibridismo e ensinoaprendizagem em contexto fronteiriço. Cadernos de PósGraduação em Letras, 13, 1-14. Recuperado de http:// www.mackenzie.br/26891.html

Maluf, M. R. (2003). Psicologia escolar: novos olhares e o desafio das práticas. In de Almeida, S. F. C. (Ed.), Psicologia escolar: ética e competências na formação e atuação profissional (pp. 135-146). Campinas, SP: Alínea.

Melo, S. M.; Stivanello, A.; da Silva, S. M. P.; da Silva, L. B. (2016). Relações conflituosas no ensino em região de fronteira. Interletras, 5(23), 1-12. Recuperado de http:// www.unigran.br/interletras/conteudo/artigos/21.pdf

Neto, F. F. M. (2012). Estudos de psicologia intercultural: nós e outros (3a. ed., vol. 2). Lisboa: Fundação Calouste Gulbenkian.

Nunes, F. G. (2011). Projetos de formação escolar para escolas em áreas de fronteira. Revista da ANPEGE, 7(1), 205-216. 
Recuperado de http://anpege.org.br/revista/ojs-2.4.6/ index.php/anpege08/article/view/156

Nunnally, J. C. (1978). Psychometric theory. New York: McGraw-Hill.

Organização das Nações Unidas para a Educação, a Ciência e a Cultura [Unesco] (2016). Educação para a cidadania global: tópicos e objetivos de aprendizagem. Brasília: Unesco. Recuperado de http://unesdoc.unesco.org/ images/0024/002448/244826POR.pdf

Pereira, J. H. V. (2002). Educação e fronteira: processos identitários de migrantes de diferentes etnias. Tese de Doutorado, Faculdade de Educação da Universidade de São Paulo, São Paulo, SP.

Pereira, J. H. V. (2009). A especificidade de formação de professores em Mato Grosso do Sul: limites e desafios no contexto da fronteira internacional. InterMeio: Revista do Programa de Pós-Graduação em Educação, 15(29), 106-119. Recuperado de http://www.intermeio.ufms.br/ revistas/29/106-119\%20-\%20v15\%20n29.pdf

Ramos, W. P. (2014). Educação física no ensino fundamental na fronteira Brasil/Paraguai: representações e identidades de professores para atuar na diversidade cultural. Dissertação de mestrado, Universidade Católica Dom Bosco, Campo Grande. Recuperado de http://site.ucdb.br/public/mddissertacoes/15367-wanessa-pucciarelo-correta.pdf

Sam, D. L.; Berry, J. W. (2010). Acculturation: when individuals and groups of different cultural backgrounds meet.
Perspectives on Psychological Science, 5(4), 472-481. doi: 10.1177/1745691610373075

Santana, M. L. S. (2018a). Interculturalismo no contexto escolar: o caso de escolas de fronteira. Tese de doutorado, Universidade Católica de Brasília, Brasília, DF.

Santana, M. L. S. (2018b). Contribuições da psicologia da educação na formação docente (s)em fronteira. Itinerarius Reflectionis, 14, 1-17. Recuperado de https://www.revistas. ufg.br/rir/article/view/47258

Segabinazi, J. D.; Giacomoni, C. H.; Dias, A. C. G.; Teixeira, M. A. P.; Moraes, D. A. O. (2010). Desenvolvimento e validação preliminar de uma escala multidimensional de satisfação de vida para adolescentes. Psicologia: Teoria e Pesquisa, 26(4), 653-659. https://dx.doi.org/10.1590/ S0102-37722010000400009

Segabinazi, J. D.; Zortea, M.; Zanon, C.; Bandeira, D. R.; Giacomoni, C. H.; Hutz, C. S. (2012). Escala de afetos positivos e negativos para adolescentes: adaptação, normatização e evidências de validade. Avaliação Psicológica, 11(1), 1-12. Recuperado de http://pepsic. bvsalud.org/scielo.php?script=sci_arttext\&pid=S167704712012000100002\&lng=pt\&nrm=iso

Szwako, J. E. L. (2012). "Del otro lado de la vereda": luta feminista e construção democrática no Paraguai pósditatorial. Tese de doutorado, Universidade Estadual de Campinas, Campinas, SP. Recuperado de http://www. repositorio.unicamp.br/handle/REPOSIP/280321

Recebido: 05 de novembro de 2018

Aprovado: 27 de novembro de 2019 